\title{
Kinship does not predict the structure of a shark social network
}

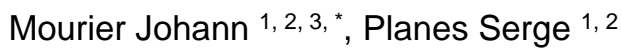

\author{
1 Univ Perpignan, USR 3278, EPHE UPVD CNRS, PSL Res Univ, F-66860 Perpignan, France. \\ 2 PSL Res Univ, EPHE, Lab Excellence CORAIL, UPVD,CNRS,USR 3278 CRIOBE, F-98729 Moorea, \\ French Polynesi, France. \\ 3 Univ Montpellier, MARBEC, CNRS, IFREMER,IRD, F-34200 Sete, France.
}

*Corresponding author : Johann Mourier, email address : johann.mourier@gmail.com

\begin{abstract}
:
Genetic relatedness in animal societies is often a factor that drives the structure of social groups. In the marine world, most studies which have investigated this question have focused on marine mammals such as whales and dolphins. For sharks, recent studies have demonstrated preferential associations among individuals from which social communities emerge. Assortment patterns have been found according to phenotypic or behavioral traits, but the role of genetic relatedness in shaping the social structure of adult shark populations has, to the best of our knowledge, never been investigated. Here, we used a social network analysis crossed with DNA microsatellite genotyping to investigate the role of the genetic relatedness in the social structure of a blacktip reef shark (Carcharhinus melanopterus) population. Based on the data from 156 groups of sharks, we used generalized affiliation indices to isolate social preferences from nonsocial associations, controlling for the contribution of sex, size, gregariousness, spatial, and temporal overlap on social associations, to test for the influence of genetic relatedness on social structure. A double-permutation procedure was employed to confirm our results and account for issues arising from potentially elevated type I and type II error rates. Kinship was not a predictor of associations and affiliations among sharks at the dyad or community levels as individuals tended to associate independently of the genetic relatedness among them. The lack of parental care in this species may contribute to the breakdown of family links in the population early in life, thereby preventing the formation of kin-based social networks.
\end{abstract}

Keywords : assortment, genetic relatedness, Carcharhinus melanopterus, elasmobranch, social organization 


\section{INTRODUCTION}

40 Group formation is an adaptive strategy, widespread across the animal kingdom, that can take

41 various forms, from temporary unstable associations to long-term stable groups in complex

42 societies (Krause and Ruxton 2002). Understanding the factors that influence the formation

43 and evolution of social groups is important in order to understand the evolution of animal

44 societies as well as to gain insight into population dynamics and to inform conservation

45 strategy (Snijders et al. 2017). Associations among individuals can provide benefits to

46 improve individual fitness, for example, by reducing predation risk or improving foraging

47 efficiency (Krause and Ruxton 2002). While individuals can benefit by simply associating

48 with other conspecifics (Kerth et al. 2011), the benefit of grouping can be enhanced by

49 associating with similar individuals, also called social assortativity. By associating with

50 individuals of the same size or the same sex, individuals are more likely to avoid conflict or

51 harassment (Dadda et al. 2005) and their risk of predation is reduced via the confusion effect

52 (Landeau and Terborgh 1986). Further, assorting with kin can also provide indirect fitness

53 benefits (Hamilton 1964). Kin assortment has been shown to provide benefits in reducing

54 aggression (Olsén and JäUrvi), increasing growth rate (Brown and Brown 1993) or allowing

55 cooperative behaviour such as predator inspection (Milinski 1987).

56 Kin structuring has received extensive attention in many animal societies, especially

57 where animals form stable breeding groups or where groups arise from the retention of

58 offspring and delayed dispersal that facilitates the development of interactions with relative

59 and kin-based groups (Wolf and Trillmich 2008; Hatchwell Ben J. 2010; Wiszniewski et al.

60 2010). In groups composed of relatives, kin selection should play a role in determining

61 cooperation among group members (Hamilton 1964), although cooperation can arise also

62 between non-kin (Clutton-Brock 2009). The role of relatedness in structuring animal societies

63 that are characterised by a dynamic fission-fusion social system has been well studied in 
64 species with parental care such as dolphins, giraffes, elephants or bats (Wittemyer et al. 2009;

65 Wiszniewski et al. 2010; Kerth et al. 2011; Carter et al. 2013), but much less is known for

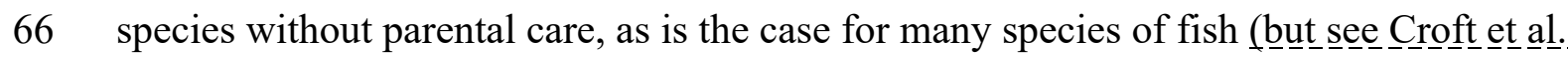

67 2012). While the link between social networks and kinship has been extensively studied in

68 terrestrial animals (Holekamp et al. 2012; Carter et al. 2013; Arnberg et al. 2015), kinship

69 structure in social networks of marine and freshwater organisms has been primarily limited to

70 marine mammals (Wiszniewski et al. 2010; Mann et al. 2012; Reisinger et al. 2017). Several

71 cetacean societies show strong kin-based social network structures. However, in fishes, kin

72 structure is less clear. Work on shoaling fish, for example, did not find kin assortment, even

73 in species that are capable of kin discrimination (Croft et al. 2012). While sharks have

74 recently been shown to be able to develop preferred associations and organise into structured

75 social networks (Mourier et al. 2018), kinship has only been explored in one case study that

76 focused on juvenile sharks (Guttridge et al. 2011) but did not find any clear influence of

77 kinship in association patterns even for juvenile sharks, highlighting a lack of information on

78 the potential for kin-based associations to arise in shark populations. Another study on

79 spotted eagle rays did not find any evidence of relatedness in the formation of groups (Newby

80 et al. 2014), although association strength was not quantified using association indices.

81 Overall, most studies that have explored the relationship between genetic relatedness and

82 social interactions have focused on highly social species and in particular, on species that

83 exhibit parental care (Wolf and Trillmich 2008; Wiszniewski et al. 2010; Kerth et al. 2011).

84 Studying less social vertebrates should significantly improve our understanding of how social

85 and genetic structure interact to shape the evolution of sociality in the animal kingdom.

86 In this study, we investigate the interaction between socio-spatial patterns and genetic

87 relatedness in a population of blacktip reef sharks (Carcharhinus melanopterus) monitored

88 over a 3-year period on the north shore of Moorea Island (French Polynesia). Sharks 
represent an interesting and unique model to explore the extent to which individuals interact

90 with genetically related associates due to ecological traits that differ from most social

91 vertebrates. Like most social animals, sharks are now increasingly recognised as being

92 capable of complex social interactions, developing preferred social associations (Guttridge et

93 al. 2009; Jacoby et al. 2010; Mourier et al. 2012), showing unexpected learning abilities

94 (Guttridge et al. 2013; Mourier et al. 2017), developing foraging strategies by associating

95 with other species to improve predation success (Labourgade et al. 2020) and developing

96 patterns of leadership and dominance hierarchy (Guttridge et al. 2011; Jacoby et al. 2016;

97 Brena et al. 2018). However, contrary to many social organisms, reef sharks do not show

98 parental care and almost all shark species drop their progeny in specific nurseries outside

99 adult habitats and leave them to interact by themselves (Mourier and Planes 2013). These

100 discrete nurseries are chosen to potentially provide the neonates with a safe environment

101 where they will spend their first months of life. Recent studies suggested that females show

102 reproductive and even natal philopatry to these particular birthing grounds (Mourier and

103 Planes 2013; Feldheim et al. 2014), suggesting that newborn sharks may have the opportunity

104 to develop strong relationships with close kin. When juvenile sharks reach a certain size or

105 age, they leave their nursery to explore a wider home range (Chapman et al. 2009); they then

106 integrate within the adult population and start interacting with older individuals, but it is not

107 known whether they coexisted with other newborn during their juvenile stage or disperse

108 alone. Therefore, while aggregations of kin are possible during the early stages, it is currently

109 unknown if they persist through adulthood after dispersal. In shark populations, interactions

110 between kin are also diluted by the presence of numerous neighbours and average relatedness

111 quickly drops with increasing group size. In some shark species, the likelihood of associating

112 with a related peer is reduced due to small litter size and a high mortality rate at the juvenile

113 stage, leading to a lack of first order relatives to reach adulthood. However, in a closed 
114 system, such as an isolated island, and in the case of blacktip reef sharks which spend their

115 entire life cycle within Moorea (Mourier and Planes 2013), relatives will have more chances

116 to encounter each other and to interact in social groups. Thus, in these conditions, the limited

117 number of related pairs might decrease the risk of inbreeding.

118 To understand the assortative forces which underpin the structural properties of the

119 system is challenging for elusive underwater animals. As the blacktip reef shark displays a

120 high degree of site fidelity (Papastamatiou et al. 2009) and shares some of its areas with

121 many conspecifics (Mourier et al. 2012), exploring this network holds the potential to work

122 out the relationship between spatial, social and genetic structure in a reef shark. Size, sex and

123 gregariousness of sharks have been shown to influence assortment at the population and

124 community levels (Mourier et al. 2012; Mourier et al. 2017). However, whether genetic

125 relatedness plays a role in structuring the network at both the individual and community

126 levels remain unknown. In particular, whether sharks benefit from associating with kin

127 remains unknown as cooperation has not been proven and social foraging may not require

128 associations with kin to improve predation success (Labourgade et al. 2020).

129 We aim to describe the social structure and to determine whether sharks had genuine

130 social preferences (caused by active choice of individuals to interact) by controlling for non-

131 social structural factors, including space use, time, phenotype, and individual gregariousness.

132 We then tested whether the social structure at different scales can be explained by the genetic

133 relatedness between individuals.

135 MATERIAL AND METHODS

136 Field observations and data collection

137 Between 2008 and 2010, observation surveys were conducted along approximately 10km 138 of coastline of the Northern reef of Moorea Island (French Polynesia) (Figure 1). The surveys 
consisted of $40 \mathrm{~min}$ dives at 7 sites along a $10 \mathrm{~km}$ portion of reef (total $=180$ dives, site $1=$

14020 , site $2=50$, site $3=8$, site $4=33$, site $5=30$, site $6=34$ and site $7=7$ ). Individual

141 blacktip reef sharks were identified by photo-identification, using unique, lifelong colour-

142 shape of the dorsal fin (Mourier et al. 2012).

143 Associations between individuals were defined using the "Gambit of the Group"

144 (Whitehead and Dufault 1999) assuming that all individuals observed together are then

145 considered as "associated". This approach is appropriate when individuals move between

146 groups and direct interactions are difficult to observe, but where groups can be easily defined

147 (Franks et al. 2010; Farine and Whitehead 2015). An experienced diver conducted a

148 stationary visual census at each site monitored, moving and identifying sharks within a $\sim 100$

149 m radius area (made possible by the high visibility conditions in these tropical waters). All

150 individuals observed during a dive were considered as part of the same group if they were

151 encountered within 10 min periods. We are confident that observed associations represented

152 true grouping structure, because groups were spatio-temporally well-defined and sharks were

153 engaged into specific social behaviour (e.g. following, parallel swwimming or milling;

154 et al.2012). To avoid the potential for weak and non-relevant associations between pairs of

155 individuals with very low number of sightings, we used a restrictive observation threshold to

156 include only individuals observed more than the median number of sightings (median $=14$;

157 mean $\pm \mathrm{sd}=14.92 \pm 8.04$; Supplementary Figure S1). Thus, all individuals seen less than 15

158 times were removed from the analyses to ensure that associations were estimated with high

159 accuracy and precision.

161 DNA sampling and laboratory procedures

162 Shark fishing sessions using rod and reel and barbless hooks were conducted to obtain tissue

163 samples for genetic analysis. Once hooked, sharks were brought alongside the boat where 
164 they were inverted and placed in tonic immobility while biological data and tissue samples

165 were collected. Each shark was identified by photo-identification of the dorsal fin, sexed and 166 measured to the nearest centimeter (Mourier et al. 2012; Mourier, Mills, et al. 2013). Fishing

167 sessions were conducted directly after underwater surveys to avoid perturbations of the

168 experimental setup (Mourier et al. 2017) and to increase the chance of getting DNA samples

169 from sharks that were part of the social network. Fishing effort was maintained until sharks

170 failed to respond to the bait (generally $<30$ min and after catching 2-3 individuals). A fin clip

171 was collected from the second dorsal fin or anal fin and samples were individually preserved

172 in 95\% ethanol and returned to the laboratory for genotyping (Mourier and Planes 2013).

173 DNA was extracted using the QIAGEN DX Universal Tissue Sample DNA Extraction

174 protocol. PCR amplification and the microsatellite loci used are described in detail in 175 previous studies (Mourier and Planes 2013; Vignaud et al. 2013; Vignaud et al. 2014). The

176 software MICROCHECKER (Van Oosterhout Cock et al. 2004) was used to test for null

177 alleles and other genotyping errors.

178 We compared the suitability of seven pairwise relatedness estimators: five non-likelihood 179 estimators (Queller and Goodnight 1989; Li et al. 1993; Ritland 1996; Lynch and Ritland 180 1999; Wang 2002) and two maximum-likelihood estimators (Milligan 2003; Wang 2007) in

181 the R package related (Pew et al. 2015) and determined that the triadic maximum-likelihood 182 estimator (TrioML__W__ang 2007) was best suited to our microsatellite panel (Supplementary 183 materials, Supplementary Figure S2) as it showed the highest correlation (i.e. 0.831) with the 184 true values and the smallest variation around the mean for every relationship (except for full185 sibs). This analysis generates simulated individuals of known relatedness based on the 186 observed allele frequencies and calculates the genetic relatedness using the different 187 estimators. The correlation between observed and expected genetic relatedness was obtained 
189 further analysis.

\section{Defining associations}

192 Using R package asnipe (Farine 2013), we calculated dyadic association strengths (i.e. 193 associations among pairs of individuals) among photo-identified individual sharks seen in

194 groups from the spatio-temporal co-occurrences, and the proportion of time two individuals

195 were observed together at the same site given that at least one was observed, using the

196 simple-ratio association index (SRI) (Cairns and Schwager 1987). The SRI is the

197 recommended association index when calibration data are unavailable (Hoppitt and Farine

198 2018).

199 To measure the diversity of associations, we calculated the social differentiation (S) in

200 the network that is the estimated coefficient of variation (standard deviation divided by mean)

201 of the true association indices. If the social differentiation of the network is 0 , then

202 relationships among members are completely homogeneous. Conversely, if the social

203 differentiation is above 1.0, there is considerable diversity in the relationships between pairs

204 of individuals within the network (Whitehead 2008). For our data, the standard error of S was

205 generated by bootstrapping (1 000 replications).

207 Potential structural factors of social associations

208 We quantified five structural factors that could affect shark association patterns: spatial

209 overlap, temporal overlap, gregariousness, and size and sex similarity for each pair of

210 individuals. Genetic relatedness was not included as a structural factor as it will be tested

211 independently when other factors are extracted. 
212 For each individual, an encounter rate (i.e., no. sightings of individual at site, divided by

213 no. sampling occasions at site) was calculated by site to define individual spatial utilization

214 (Supplementary Figure S3). We then generated a Bray-Curtis similarity matrix of space use

215 to construct a matrix of spatial overlap between individuals using R package "vegan" (Dixon

216 2003).

217 Individuals using an area at the same time are more likely to be associated with each

218 other. The study period corresponds to a total of 28 months between February 2008 and June

219 2010. The temporal overlap was calculated as the custom SRI calculated on whether pairs

220 were observed in the study area within sampling periods of 60 days.

221 Gregariousness was calculated following Whitehead and James's (2015) correction,

222 where the gregariousness predictor between two individuals ( $a$ and $b$ ) is the log of the sum of

223 the association indices involving $a$ (except the $a b$ index) multiplied by the sum of those

224 involving $b$ (except the $b a$ index): $\mathrm{G}_{a b}=\log \left(\Sigma \mathrm{SRI}_{a} \Sigma \mathrm{SRI}_{b}\right)$ where $\Sigma \mathrm{SRI}_{a}$ and $\Sigma \mathrm{SRI}_{b}$ are the

225 sums of all the SRIs for individuals $a$ and $b$, respectively.

226 Shark length was classified into size classes ranging from 1 to $6(1: \mathrm{TL}<110 \mathrm{~cm} ; 2$ :

227 110-119 cm; 3: 120-129 cm; 4: 130-139 cm; 5: 140-150 cm; 6: TL > $150 \mathrm{~cm})$. For sex and

228 size similarity, we constructed a binary matrix in which elements $\mathrm{a}_{i j}=1$ when individuals $i$

229 and $j$ were of the same class and $\mathrm{a}_{i j}=0$ otherwise (sex class, 1 if same sex, 0 if not; size class,

2301 if same size class, 0 if not).

231

232 Influence of structural factors on social associations

233 We quantified the contribution of all five structural factors in driving social patterns with

234 a multiple regression quadratic assignment procedure (MRQAP) modified by Farine (2013)

235 that enables null models built from pre-network data permutations to be used in conjunction

236 with a MRQAP regression. This approach was shown to be more accurate than classic 
237 MRQAP procedures (Farine 2017). We assessed possible linear relationships between the

238 social associations and the structural factors using the SRI association matrix as the

239 dependent variables and the matrices representing pairwise similarity of each of the five

240 structural factors as independent variables. We used 20,000 permutations to build randomized

241 distributions to compare with the empirical coefficient. The $P$-values were the proportion of

242 the estimated coefficient regression which were smaller or greater than what would have been

243 expected by chance. We used the mrqap.custom.null function from asnipe R package (Farine

244 2013) to run MRQAP tests in R v. 3.3.0 (R Core Team 2019).

\section{Removing the effects of structural factors from associations}

247 We developed generalized affiliation indices (GAII, Whitehead

248 remove the effects of the significant structural factors from the associations and test the

249 existence of true affiliations between dyads (i.e. active association preferences). For this, we

250 fitted a binomial generalized linear model (GLM) with the unfolded SRI matrix as the

251 dependent variable, and the significant structural factors selected from the MRQAP as

252 independent variables. GAI represents the assortment of individuals not explained by the

253 significant structural factors and corresponds to the deviance residuals of the model. The

254 model was: $\mathrm{SRI} \sim \mathrm{TO}+\mathrm{SO}$, where SRI is the association matrix, $\mathrm{TO}$ is the temporal overlap

255 matrix and SO is the spatial overlap matrix (as only TO and SO were significant factors in the 256 MRQAP, Table 1).

\section{Social preferences and null models}

259 We used a null model to test both for social preferences and the significance of the

260 observed network modularity. We generated 20,000 randomized association and affiliation

261 networks based on 25,000 data-stream permutations of the raw observation data with a 
262 swapping algorithm (Bejder et al. 1998). We permuted the empirical group-by-individual

263 matrix constraining the number of groups, individuals and occurrences (matrix dimension

264 and fill), group size (row totals) and individual frequency of observation (column totals). To

265 minimize the effect of initial values potentially correlated to the empirical data, we removed

266 the first 5,000 randomized matrices. From the randomised group-by-individual matrix, we

267 calculated a simple-ratio index association matrix, with which we built a generalized

268 affiliation index using the same predictors selected via MRQAP for the empirical data. We

269 used a modified version of R codes available from Machado et al. (2019) to build null models

270 and to calculate SRI, GAI and modularity.

271 We compared the standard deviation (SD) of the observed simple-ratio index (SRI) and

272 the SD of the observed generalized affiliation index (GAI) with the distribution of the SD of

273 corresponding randomized SRI and GAI matrices generated by the null models detailed

274 above. An observed SD significantly higher than the null expectation indicates the presence

275 of preferred and avoided associations and affiliations. We also tested for strongly connected

276 social communities by comparing the empirical modularity (Q) (Newman 2006) of SRI and

277 positive GAI matrices with that of the randomized matrices. Empirical SD and Q values were

278 considered statistically significant if they fell outside the 95\% confidence interval of their

279 randomized distributions.

280

281 Genetic relatedness, social structure and sex differences

282 To assess whether relatedness differs for same-sex dyads, we constructed three binary

283 matrices $(0,1)$, each encoding the presence of a certain dyad type (female-female, male-male

284 or female-male). We then tested for a correlation with the relatedness matrix using three

285 Mantel tests (20,000 permutations), via the vegan R package (Dixon 2003). 
287 correlation between the SRI and GAI matrices and the pairwise genetic relatedness among

288 sharks using Mantel tests and compared the test statistics to those of the 20,000 permuted

289 networks.

290 We also compared the gregariousness of individual sharks between the sexes. For this,

291 we used two measures of gregariousness: node degree (or binary degree) which is the number

292 of direct neighbours each individual is connected to in the network and node strength (or

293 weighted degree) that is the sum of associations of an individual. We then used these network

294 metrics in order to determine whether males and females differed in their gregariousness. We

295 constructed generalized linear models (GLMs) to test how sex affected the observed network

296 degree (degree $\sim$ sex) and strength (strength $\sim$ sex). We ran these same models with

297 randomized permutations of the network data to evaluate statistical significance (Farine and

298 Whitehead 2015; Farine 2017).

299 To determine whether individuals within groups (size class and communities) were more

300 or less closely related than expected, we compared the observed values for each group against

301 a distribution of expected relatedness values generated by randomly shuffling individuals

302 between groups for 1000 permutations, where size was kept constant, using the R

303 package related (Pew et al. 2015). If the observed mean relatedness was greater than that of

304 the permuted data, then the null hypothesis which predicted that the mean within-community

305 relatedness is random, was rejected.

306 If only a few closely related individuals were present, then it is possible that their within-

307 community overabundance compared to between social communities might not be detected

308 using mean coefficient of relatedness (Buston et al. 2009). In turn, we verified whether the

309 proportion of closely related pairs was higher within than between social communities using

310 a chi-squared test following the same approach as the preceding analysis with mean 
311 relatedness. We compared the $\chi^{2}$ statistics of the observed difference in proportions of

312 relatedness values above a certain threshold between within- and between-communities to

313 that of expected relatedness values generated by randomly shuffled individuals between

314 community groups for 1000 permutations and keeping size constant. We tested with a

315 threshold relatedness value of 0.25 corresponding to the theoretical relatedness of half-sibs.

\section{RESULTS}

\section{Data summary}

319 Of 241 catalogued sharks (150 males, 91_females; Mourier_et al. 2012), 49 (36 males, 13

320 females) were observed on more than 15 occasions (mean resightings $=14.92 \pm 8.04 \mathrm{SD}$,

321 Supplementary Figure S1). A total of 225 adult sharks were genotyped from the studied area.

322 From the 49 sharks included in our social network analyse, 87\% (43) were genotyped.

323 Therefore, 43 individuals (30 males, 13 females) were included in the remaining analyses.

324 This resulted in 156 observed groups (mean group size $=8.60 \pm 4.92 \mathrm{SD}$ ). From the 17

325 microsatellite markers taken from our previous study (Mourier and Planes 2013), the

326 presence of null alleles was detected at Cli12 which was then removed from our dataset for

327 further genetic analyses. We conducted the genetic analyses with 16 loci (Supplementary

328 Table S1).

\section{Social structure}

331 The social differentiation of the population was higher than $1(\mathrm{~S} \pm \mathrm{SE}=1.474 \pm 0.037)$,

332 revealing a diverse range of associations and a well-differentiated society. The most

333 significant predictors of shark associations were the temporal and spatial overlaps, which

334 explained $94 \%$ of the total variance in SRI (MRQAP results, Table 1). 
336 SRI was higher than the random SD. When GAI removed the influence of temporal and

337 spatial overlaps from SRI, we also rejected the null hypothesis of random affiliations (Figure

338 2a) demonstrating the presence of preferred social affiliations. At the population level, the

339 modularity (Q) of the association (SRI) and affiliation (GAI) networks were higher than

340 expected by chance (Figure 2b). While the three communities from the SRI network had

341 distinct use of space, some communities from the GAI network had similar spatial

342 distributions (e.g., communities yellow and purple, Figure 2c).

\section{Crossing of genetic relatedness and association patterns}

345 When testing for kin-biased relatedness, adult male-male (MM), female-female (FF) and

346 male-female (MF) dyads did not have clear higher or lower genetic relatedness (Mantel test:

$347 \mathrm{MM}, \mathrm{r}=-0.012, \mathrm{n}=31, \mathrm{P}=0.061 ; \mathrm{FF}, \mathrm{r}=-0.019, \mathrm{n}=12, \mathrm{P}=0.685 ; \mathrm{MF}, \mathrm{r}=0.023, \mathrm{n}=43, \mathrm{P}$

$348=0.259)$. In addition, mean genetic relatedness was not higher within than between size

349 classes $($ mean $\mathrm{r}=0.043$, random $95 \% \mathrm{CI}=0.058-0.065, \mathrm{P}=0.88$; Supplementary materials,

350 Table S2). While individuals were relatively spatially clustered, genetic relatedness appeared

351 much more homogeneously distributed across individuals and space (Mantel test between

352 matrices of spatial overlap and genetic relatedness: $\mathrm{r}=0.011, \mathrm{n}=43, \mathrm{P}=0.351$;

353 Supplementary Figure S4).

354 Average pairwise relatedness among individuals was $0.062 \pm 0.001$ (mean $\pm \mathrm{SE}$ ) ranging

355 from 0 to 0.774 . Associations were only significantly positively correlated with genetic

356 relatedness between males (Mantel test: $\mathrm{r}=0.103, \mathrm{P}=0.026$ ) but no significant correlation

357 was found between GAI and genetic relatedness for any sex dyad (Table 2). Males were

358 generally more gregarious than females, as they significantly interacted with more 
individuals (higher degree) but did not have stronger relationships (higher strength) (Table 3,

360 Figure 3).

361 Within-community relatedness estimate was inferred for each community and index (SRI

362 and GAI, Table 4). Relatedness within all communities was not higher than expected if

363 communities were randomly organized (SRI network: within mean $\pm \mathrm{SE}=0.071 \pm 0.005$,

364 between mean $\pm \mathrm{SE}=0.058 \pm 0.003, \mathrm{P}=0.093$; GAI network: within mean $\pm \mathrm{SE}=0.060 \pm$

3650.005 , between mean $\pm \mathrm{SE}=0.063 \pm 0.005, \mathrm{P}=0.722)$ (Table 4).

366 Among the 903 potential pairs, 39 (4.31\%) had values higher than 0.25 . In addition, there

367 was no higher proportion of close relatives within than between communities for relatedness

368 value $r>0.25$ for SRI (chi-squared test: $n_{\text {within/between }}=17 / 22$, d.f. $=1, \chi^{2}=0.928, P=0.119$ )

369 and GAI (chi-squared test: $\mathrm{n}_{\text {within/between }}=8 / 35$, d.f. $\left.=1, \chi^{2}=0.386, \mathrm{P}=0.326\right)($ Figure 4).

370 Together, these results suggest that no differences exist for within- and between-

371 community membership with respect to the genetic relatedness of their members.

\section{DISCUSSION}

We found a fine-scale social structure in blacktip reef sharks in Moorea. Taking into account the confounding effects of 5 structural variables (spatial and temporal overlap, gregariousness, size and sex), which are known to influence association patterns (e.g. Godde et al._2013; Diaz-Aguirre et al. 2019; Machado_et_al. 2019;_Perryman et al._2019), we found that blacktip reef sharks in Moorea had both preferred associations and affiliations. However,

379 social proximity was not predicted by the genetic relatedness between sharks both at the 380 association, affiliation and community levels. At the dyad level, only male-male associations, 381 but not affiliations, were slightly correlated with genetic relatedness. In addition, individuals 382 had low probabilities of interacting with a close-kin which could explain the lack of influence 383 of kinship in structuring the social network in this population. These results therefore suggest 
384 that genetic relatedness does not drive the structure of the social network in this shark

385 population.

386 Compared to previous work conducted on this population (Mourier et al. 2012) which

387 only analysed social structure through associations among sharks, the present study also

388 considered the effects of two structural variables to estimate affiliation indices. Affiliations

389 are an increasingly used method to investigate the true social interactions experienced by

390 animals (Whitehead and James 2015), in particular by considering the strong correlation that

391 can exist between space use overlap and association indices in a variety of taxa (e.g.,_﹎. Mourier.

392 et al._2012; Carter_et_al. 2013; Best et_al.2014). In our study, the network built from

393 associations using the simple ratio index (SRI) was composed of three main communities

394 relatively spatially separated and only low overlap (Figure 2). When removing the influence

395 of spatial and temporal overlap from association patterns, the network built from the

396 generalized affiliation indices (GAI) revealed five communities that were less spatially

397 separated. This means that associations between sharks were the result of more than just

398 similarities in habitat use or overlaps in time, indicating that individuals actively chose to

399 group with preferred social partners. The differences between the three SRI communities in

400 the present study and the four communities found in Mourier et al. (2012) can be due to the

401 high threshold we used that may highlight only string relationships and the use of SRI instead

402 of HWI. To our knowledge, only one study on elasmobranchs has investigated social

403 structure using GAI, demonstrating that manta rays also preferred affiliations (Perryman et al.

404 2019). Individuals' site preferences and being present in the study at the same time was a

405 strong predictor of association between pairs. Site fidelity is often a prerequisite for sociality,

406 creating an environment for social relationships to develop and the emergence of social

407 preferences. However, the presence of preferred social affiliations demonstrates that sharks

408 show active social preferrences that do not rely on preferrences for sites and periods. Our 
study confirms that the observed shark social structure resembles that of a fission-fusion

410 society characterized by an open and fluid social structure, long-term social recognition and a

411 high number of potential affiliates, which is flexible depending on environemental

412 conditions.

413 Among the adult sharks in our population, there was a generally low level of

414 relatedness, and only a small number of dyads had close familial relatives. Interactions

415 frequently occurred between distant kin and non-kin. This implies that the social structure

416 among adult blacktip reef sharks was not based on associations between close kin as

417 demonstrated by our analyses which compared association and affiliation patterns with

418 genetic relatedness among dyads at the pairwise or community levels. This is confirmed by

419 the low number of close kin available for each shark in the population $(<6 \%$ pairs with $r>$

420 0.25), thereby limiting the probability of an individual to encounter a family member and to

421 develop strong associations with them. The lack of genetic relatedness structure within size

422 classes and the lack of decreasing genetic relatedness as sharks grow also suggests that

423 juveniles are unlikely to leave their nursery ground with other kin. If young sharks were

424 developing and maintaining strong bonds with their littermates throughout their entire life,

425 we would have expected to find high mean relatedness and high proportion of close kin

426 across all size classes. The low relatedness we found within each size class indicates that

427 sharks favoured associations with non-kin. These results can be explained in part by the life

428 history and life cycle of blacktip reef sharks. In fact, in contrast to most social animals that

429 show some forms of family structure and parental care, female reef-associated sharks such as

430 blacktip reef shark, leave their pups in their nursery after birth (Mourier and Planes 2013).

431 Moreover, litter size in this species does not exceed five pups (Mourier, Mills, et al. 2013)

432 while litter size in Moorea was limited to a maximum of two pups (Mourier and Planes

433 2013). In addition, blacktip reef sharks follow a yearly breeding cycle with females giving 
434 birth every year and potentially being fertilized by multiple males within or across years,

435 which increases the probability of having maternal and paternal half-siblings. Our ongoing

436 long-term nursery monitoring shows that capture probabilities rapidly decline after March

437 (unpublished data), 2 to 3 months after parturition, which suggests a dramatic mortality rate

438 within the nursery areas during the first months of life (i.e. survival rate expected to be

439 inferior to $50 \%$ during the first year of life). Together with a small litter size and absence of

440 parental care, this high mortality rate, which is common in many shark species, is likely to

441 limit the opportunity to find family members and develop strong affiliations with close

442 relatives at adulthood. Even in nurseries, juvenile lemon sharks did not clearly assort by

443 relatedness (Guttridge et al. 2011), even if the probability of finding a relative is higher for

444 this species with a larger litter size. When juvenile sharks grow, they progressively explore

445 their environment and increase their home range (Chin A et al. 2013), creating an opportunity

446 to find related individuals such as parents or maternal half-siblings from previous

447 reproductive seasons. At adulthood, our results confirm that preferred associations and

448 affiliations are not driven by genetic relatedness as sharks are associating with conspecifics of

449 variable genetic distances. This suggests that sharks might not have the ability for kin

450 recognition simply based on visual or olfactory cues and that kin-based preferred associations

451 and affiliations may only develop within nursery areas from increased familiarity with

452 littermates, or that they are not seeking for associations with related individuals. Through

453 investigation of social groups of spotted eagle rays Aetobatus narinari in Florida, Newwby et

454 al._(2014) found no kin-structure in the social organization, although the analysis was based

455 on group composition rather that quantitatively inferred using association indices. However,

456 our results revealed that males sighly preferred to associate with other related males but this

457 tendency was not confirmed for affiliations (accounting for spatial and temporal structural

458 components). This suggests that genetic relatedness among males was spatially structured 
and that males may disperse less than females. The lack of differences in relatedness between

460 males and females suggests that the risk of inbreeding might be low if these interactions

461 represented potential mating pairs and not only social bonds.

462

463

The emerging literature suggests that genetic structure of animal social networks can

464 vary dramatically, from highly cohesive kin-based groups like African elephants (Loxodonta

465 africana) (Archie et al. 2006) or spotted hyenas (Crocuta crocuta) (Holekamp et al. 2012), to

466 groups with moderate levels of genetic relatedness due to limited dispersal like the Galápagos

467 sea lion (Zalophus wollebaeki) (Wolf and Trillmich 2008) or the eastern grey kangaroo

468 (Macropus giganteus) (Best et al. 2014), or to groups with little to no genetic relatedness like

469 guppies (Poecilia reticulata) (Croft et al. 2012), the common raccoon (Procyon lotor)

470 (Hirsch et al. 2013) or migratory golden-crowned sparrows (Zonotrichia atricapilla)

471 (Arnberg et al. 2015). These patterns of variation provide opportunities to explore how

472 ecological factors interact with kinship to produce variations in the structures of animal

473 societies. Kinship is expected to promote the evolution of cooperation and sociality in

474 animals (Hamilton 1964). However, our understanding of the evolution of sociality results to

475 a great extent from the study of closed societies, in which interactions mainly involve

476 relatives and can hence be explained by kin selection (Hamilton 1964). However, the kin

477 selection theory has recently been challenged by results from studies showing that fitness

478 benefit can emerge in social groups composed mainly of non-relatives (e.g., Cameron et al.

479 2009; Riehl 2011; Wilkinson et al. 2016). In many natural populations, dispersal tends to be

480 limited, favouring local competition between neighbours and the emergence of a social

481 component, whether it be selfish, aggressive, cooperative or altruistic (Lehmann and Rousset

482 2010). But how social behaviours translate into fitness costs and benefits depends

483 considerably on life-history features, as well as on local demographic and ecological 
conditions. The fission - fusion social dynamics lead to unstable group membership, and

485 dispersal and occasional recruitment of unrelated individuals lead to low average relatedness

486 in groups. Then under such conditions, selection is not expected to favour kin recognition

487 mechanisms based on familiarity alone.

488 Therefore, contrary to the kin selection hypothesis which predicts stronger associations

489 among kin, sharks tended to assort randomly according to relatedness. As kinship does not

490 explain the strength of social affiliations in blacktip reef sharks, the question remains as to

491 how and why sharks form preferred associations and affiliations organised in social

492 communities (Mourier et al. 2012). Although cooperation has been mainly explained in the

493 context of kin selection, there might be potential benefits of non-kin sociality in blacktip reef

494 sharks such as for other animals in which association with non-kin emerges via reciprocal

495 altruism (Carter and Wilkinson 2013; Wilkinson et al. 2016). While evidence of shark

496 cooperation has not been confirmed, gregarious behaviour can have several benefits in sharks

497 (Jacoby et al. 2012), including increased foraging success by hunting in groups (Weideli et al.

498 2015; Mourier et al. 2016), protection from predators (Mourier, Planes, et al. 2013), or

499 increased tolerance relationships and reduced aggression rate (Brena et al. 2018).

500 Heterospecific foraging associations have been found to develop and increase predation

501 success (Labourgade et al. 2020), which suggests that sharks can benefit from hunting

502 associations without associating with kin. These benefits do not necessarily imply kin

503 selection and can simply build on the development of familiarity from repeated interactions.

504 Social structure in reef sharks can arise from multiple simple ecological factors such as the

505 distribution of resources in space and time leading to aggregations of individuals even in the

506 absence of benefits of direct social affiliation (Ramos-Fernández et al. 2006) or mitigation of

507 the cost of unnecessary aggression when competing for resources mediated by individual

508 recognition (Brena et al. 2018). Regardless of the exact cause of social preferences in reef 
sharks, the absence of kinship as an important factor in structuring association patterns

510 suggests that there are important benefits of sociality in sharks that we still need to uncover.

511 With an increasing use of social network analyses applied to shark populations (Mourier et al.

512 2018), future work on social networks and genetic relatedness in different populations or

513 species is necessary to confirm our results and to improve our understanding of population

514 dynamics in sharks and the evolution of sociality.

\section{SUPPLEMENTARY MATERIAL}

517 Supplementary information including two tables and four figures can be found online.

\section{REFERENCES}

Archie EA, Moss CJ, Alberts SC. 2006. The ties that bind: genetic relatedness predicts the fission and fusion of social groups in wild African elephants. Proc R Soc Lond B Biol Sci. 273(1586):513-522. doi:10.1098/rspb.2005.3361.

Arnberg NN, Shizuka D, Chaine AS, Lyon BE. 2015. Social network structure in wintering golden-crowned sparrows is not correlated with kinship. Mol Ecol. 24(19):5034-5044.

Bejder L, Fletcher D, Bräger S. 1998. A method for testing association patterns of social animals. Anim Behav. 56(3):719-725. doi:10.1006/anbe.1998.0802.

Best EC, Dwyer RG, Seddon JM, Goldizen AW. 2014. Associations are more strongly correlated with space use than kinship in female eastern grey kangaroos. Anim Behav. 89:110. doi:10.1016/j.anbehav.2013.12.011.

531 Brena PF, Mourier J, Planes S, Clua EE. 2018. Concede or clash? Solitary sharks competing for food assess rivals to decide. Proc R Soc B. 285(1875):20180006.

533 doi:10.1098/rspb.2018.0006.

534 Brown GE, Brown JA. 1993. Social dynamics in salmonid fishes: do kin make better 535 neighbours? Anim Behav. 45(5):863-871. doi:10.1006/anbe.1993.1107.

536 Buston PM, Fauvelot C, Wong MYL, Planes S. 2009. Genetic relatedness in groups of the 537 humbug damselfish Dascyllus aruanus: small, similar-sized individuals may be close kin. 538 Mol Ecol. 18(22):4707-4715. doi:10.1111/j.1365-294X.2009.04383.x.

539 Cairns SJ, Schwager SJ. 1987. A comparison of association indices. Anim Behav.

540 35(5):1454-1469. doi:10.1016/S0003-3472(87)80018-0. 
Cameron EZ, Setsaas TH, Linklater WL. 2009. Social bonds between unrelated females increase reproductive success in feral horses. Proc Natl Acad Sci. 106(33):13850-13853. doi:10.1073/pnas.0900639106.

544 Carter GG, Wilkinson GS. 2013. Food sharing in vampire bats: reciprocal help predicts 545 donations more than relatedness or harassment. Proc R Soc B Biol Sci. 280(1753):20122573. 546 doi:10.1098/rspb.2012.2573.

547 Carter KD, Seddon JM, Frère CH, Carter JK, Goldizen AW. 2013. Fission-fusion dynamics 548 in wild giraffes may be driven by kinship, spatial overlap and individual social preferences. 549 Anim Behav. 85(2):385-394. doi:10.1016/j.anbehav.2012.11.011.

550 Chapman DD, Babcock EA, Gruber SH, Dibattista JD, Franks BR, Kessel SA, Guttridge T, 551 Pikitch EK, Feldheim KA. 2009. Long-term natal site-fidelity by immature lemon sharks 552 (Negaprion brevirostris) at a subtropical island. Mol Ecol. 18(16):3500-3507.

553 doi:10.1111/j.1365-294X.2009.04289.x.

554 Chin A, Heupel MR, Simpfendorfer CA, Tobin AJ. 2013. Ontogenetic movements of juvenile blacktip reef sharks: evidence of dispersal and connectivity between coastal habitats and coral reefs. Aquat Conserv Mar Freshw Ecosyst. 23(3):468-474. doi:10.1002/aqc.2349.

557 Clutton-Brock T. 2009. Cooperation between non-kin in animal societies. Nature.

558 462(7269):51-57. doi:10.1038/nature08366.

559 Croft DP, Hamilton PB, Darden SK, Jacoby DMP, James R, Bettaney EM, Tyler CR. 2012. 560 The role of relatedness in structuring the social network of a wild guppy population.

561 Oecologia. 170(4):955-963. doi:10.1007/s00442-012-2379-8.

562 Dadda M, Pilastro A, Bisazza A. 2005. Male sexual harassment and female schooling behaviour in the eastern mosquitofish. Anim Behav. 70(2):463-471. doi:10.1016/j.anbehav.2004.12.010.

570 Farine DR. 2013. Animal social network inference and permutations for ecologists in R using

Diaz-Aguirre F, Parra GJ, Passadore C, Möller L. 2019. Genetic relatedness delineates the social structure of southern Australian bottlenose dolphins. Behav Ecol. 30(4):948-959. doi:10.1093/beheco/arz033.

572 Farine DR. 2017. A guide to null models for animal social network analysis. Methods Ecol

573 Evol.:n/a-n/a. doi:10.1111/2041-210X.12772.

574 Farine DR, Whitehead H. 2015. Constructing, conducting and interpreting animal social 575 network analysis. J Anim Ecol. 84(5):1144-1163. doi:10.1111/1365-2656.12418.

576 Feldheim KA, Gruber SH, DiBattista JD, Babcock EA, Kessel ST, Hendry AP, Pikitch EK, 577 Ashley MV, Chapman DD. 2014. Two decades of genetic profiling yields first evidence of 578 natal philopatry and long-term fidelity to parturition sites in sharks. Mol Ecol. 23(1):110579 117. doi: $10.1111 / \mathrm{mec} .12583$. 
582 Godde S, Humbert L, Côté SD, Réale D, Whitehead H. 2013. Correcting for the impact of 583 gregariousness in social network analyses. Anim Behav. 85(3):553-558.

584 doi:10.1016/j.anbehav.2012.12.010.

585 Guttridge TL, Dijk S van, Stamhuis EJ, Krause J, Gruber SH, Brown C. 2013. Social learning 586 in juvenile lemon sharks, Negaprion brevirostris. Anim Cogn. 16(1):55-64.

587 doi:10.1007/s10071-012-0550-6.

588 Guttridge TL, Gruber SH, DiBattista JD, Feldheim KA, Croft DP, Krause S, Krause J. 2011. 589 Assortative interactions and leadership in a free-ranging population of juvenile lemon shark 590 Negaprion brevirostris. Mar Ecol Prog Ser. 423:235-245. doi:10.3354/meps08929.

591 Guttridge TL, Gruber SH, Gledhill KS, Croft DP, Sims DW, Krause J. 2009. Social 592 preferences of juvenile lemon sharks, Negaprion brevirostris. Anim Behav. 78(2):543-548. 593 doi:10.1016/j.anbehav.2009.06.009.

594 Hamilton WD. 1964. The genetical evolution of social behaviour. I. J Theor Biol. 7(1):1-16. doi:10.1016/0022-5193(64)90038-4.

600 racoon social network structure. Anim Behav. 85(2):463-470.

601 doi:10.1016/j.anbehav.2012.12.011.

602 Holekamp KE, Smith JE, Strelioff CC, Van Horn RC, Watts HE. 2012. Society, demography 603 and genetic structure in the spotted hyena. Mol Ecol. 21(3):613-632. doi:10.1111/j.1365604 294X.2011.05240.x.

605 Hoppitt WJE, Farine DR. 2018. Association indices for quantifying social relationships: how 606 to deal with missing observations of individuals or groups. Anim Behav. 136:227-238.

607 doi:10.1016/j.anbehav.2017.08.029.

608 Jacoby DMP, Busawon DS, Sims DW. 2010. Sex and social networking: the influence of 609 male presence on social structure of female shark groups. Behav Ecol. 21(4).

610 doi:10.1093/beheco/arq061. [accessed 2017 Jan 4].

611 http://beheco.oxfordjournals.org/content/early/2010/05/09/beheco.arq061.

612 Jacoby DMP, Croft DP, Sims DW. 2012. Social behaviour in sharks and rays: analysis, 613 patterns and implications for conservation. Fish Fish. 13(4):399-417. doi:10.1111/j.1467614 2979.2011.00436.x.

615 Jacoby DMP, Papastamatiou YP, Freeman R. 2016. Inferring animal social networks and 616 leadership: applications for passive monitoring arrays. J R Soc Interface. 13(124):20160676.

617 doi:10.1098/rsif.2016.0676. 
618 Kerth G, Perony N, Schweitzer F. 2011. Bats are able to maintain long-term social

619 relationships despite the high fission-fusion dynamics of their groups. Proc R Soc Lond B

620 Biol Sci. 278(1719):2761-2767. doi:10.1098/rspb.2010.2718.

621 Krause J, Ruxton GD. 2002. Living in Groups. OUP Oxford.

622 Labourgade P, Ballesta L, Huveneers C, Papastamatiou Y, Mourier J. 2020. Heterospecific

623 foraging associations between reef-associated sharks: first evidence of kleptoparasitism in

624 sharks. Ecology.

625 Landeau L, Terborgh J. 1986. Oddity and the 'confusion effect' in predation. Anim Behav.

626 34(5):1372-1380. doi:10.1016/S0003-3472(86)80208-1.

627 Lehmann L, Rousset F. 2010. How life history and demography promote or inhibit the

628 evolution of helping behaviours. Philos Trans R Soc Lond B Biol Sci. 365(1553):2599-2617.

629 doi:10.1098/rstb.2010.0138.

630 Li CC, Weeks DE, Chakravarti A. 1993. Similarity of DNA fingerprints due to chance and 631 relatedness. Hum Hered. 43(1):45-52.

632 Lynch M, Ritland K. 1999. Estimation of Pairwise Relatedness With Molecular Markers.

633 Genetics. 152:1753-1766.

634 Machado AMS, Cantor M, Costa APB, Righetti BPH, Bezamat C, Valle-Pereira JVS, 635 Simões-Lopes PC, Castilho PV, Daura-Jorge FG. 2019. Homophily around specialized 636 foraging underlies dolphin social preferences. Biol Lett. 15(4):20180909.

637 doi:10.1098/rsbl.2018.0909.

638 Mann J, Stanton MA, Patterson EM, Bienenstock EJ, Singh LO. 2012. Social networks reveal 639 cultural behaviour in tool-using dolphins. Nat Commun. 3:980. doi:10.1038/ncomms1983.

640 Milinski M. 1987. TIT FOR TAT in sticklebacks and the evolution of cooperation. Nature. 641 325(6103):433-435. doi:10.1038/325433a0.

642 Milligan BG. 2003. Maximum-Likelihood Estimation of Relatedness. Genetics.

643 163(3):1153-1167.

644 Mourier J, Brown C, Planes S. 2017. Learning and robustness to catch-and-release fishing in 645 a shark social network. Biol Lett. 13(3):20160824. doi:10.1098/rsbl.2016.0824.

646 Mourier J, Lédée EJI, Guttridge TL, Jacoby DMP. 2018. Network analysis and theory in 647 shark ecology - methods and applications. In: Shark Research: Emerging Technologies and 648 Application for the Study of Shark Biology. Carrier J, Heithaus M and Simpfendorfer C. 649 CRC Press. p. 337-356.

650 Mourier J, Maynard J, Parravicini V, Ballesta L, Clua E, Domeier ML, Planes S. 2016. 651 Extreme Inverted Trophic Pyramid of Reef Sharks Supported by Spawning Groupers. Curr 652 Biol. 26(15):2011-2016. doi:10.1016/j.cub.2016.05.058.

653 Mourier J, Mills SC, Planes S. 2013. Population structure, spatial distribution and life-history 654 traits of blacktip reef sharks Carcharhinus melanopterus. J Fish Biol. 82(3):979-993.

655 doi:10.1111/jfb.12039. 
Mourier J, Planes S. 2013. Direct genetic evidence for reproductive philopatry and associated fine-scale migrations in female blacktip reef sharks (Carcharhinus melanopterus) in French Polynesia. Mol Ecol. 22(1):201-214. doi:10.1111/mec.12103.

659 Mourier J, Planes S, Buray N. 2013. Trophic interactions at the top of the coral reef food 660 chain. Coral Reefs. 32(1):285-285. doi:10.1007/s00338-012-0976-y.

661 Mourier J, Vercelloni J, Planes S. 2012. Evidence of social communities in a spatially structured network of a free-ranging shark species. Anim Behav. 83(2):389-401. doi:10.1016/j.anbehav.2011.11.008.

664 Newby J, Darden T, Bassos-Hull K, Shedlock AM. 2014. Kin structure and social 665 organization in the spotted eagle ray, Aetobatus narinari, off coastal Sarasota, FL. Environ 666 Biol Fishes. 97(9):1057-1065. doi:10.1007/s10641-014-0289-9.

667 Newman MEJ. 2006. Finding community structure in networks using the eigenvectors of 668 matrices. Phys Rev E. 74(3):036104. doi:10.1103/PhysRevE.74.036104.

669 Olsén KH, JäUrvi T. Effects of kinship on aggression and RNA content in juvenile Arctic 670 charr. J Fish Biol. 51(2):422-435. doi:10.1111/j.1095-8649.1997.tb01676.x.

671 Papastamatiou YP, Lowe CG, Caselle JE, Friedlander AM. 2009. Scale-dependent effects of 672 habitat on movements and path structure of reef sharks at a predator-dominated atoll.

673 Ecology. 90(4):996-1008. doi:10.1890/08-0491.1.

674 Perryman RJY, Venables SK, Tapilatu RF, Marshall AD, Brown C, Franks DW. 2019. Social preferences and network structure in a population of reef manta rays. Behav Ecol Sociobiol.

676 73(8):114. doi:10.1007/s00265-019-2720-x.

677 Pew J, Muir PH, Wang J, Frasier TR. 2015. related: an R package for analysing pairwise 678 relatedness from codominant molecular markers. Mol Ecol Resour. 15(3):557-561.

679 doi:10.1111/1755-0998.12323.

680 Queller DC, Goodnight KF. 1989. Estimating Relatedness Using Genetic Markers. Evolution. 681 43(2):258-275. doi:10.1111/j.1558-5646.1989.tb04226.x.

682 R Core Team. 2015. R: a language and environment for statistical computing. Vienna, 683 Austria: R Computing Foundation for Science.

684 Ramos-Fernández G, Boyer D, Gómez VP. 2006. A complex social structure with fission685 fusion properties can emerge from a simple foraging model. Behav Ecol Sociobiol.

686 60(4):536-549. doi:10.1007/s00265-006-0197-x.

687 Reisinger RR, Beukes (née Janse van Rensburg) C, Hoelzel AR, de Bruyn PJN. 2017.

688 Kinship and association in a highly social apex predator population, killer whales at Marion 689 Island. Behav Ecol. 28(3):750-759. doi:10.1093/beheco/arx034.

690 Riehl C. 2011. Living with strangers: direct benefits favour non-kin cooperation in a 691 communally nesting bird. Proc R Soc Lond B Biol Sci. 278(1712):1728-1735.

692 doi:10.1098/rspb.2010.1752. 
693 Ritland K. 1996. Estimators for pairwise relatedness and individual inbreeding coefficients.

694 Genet Res. 67(2):175-185. doi:10.1017/S0016672300033620.

695 Snijders L, Blumstein DT, Stanley CR, Franks DW. 2017. Animal Social Network Theory

696 Can Help Wildlife Conservation. Trends Ecol Evol. 32(8):567-577.

697 doi:10.1016/j.tree.2017.05.005.

698 Van Oosterhout Cock, Hutchinson William F., Wills Derek P. M., Shipley Peter. 2004.

699 micro-checker: software for identifying and correcting genotyping errors in microsatellite

700 data. Mol Ecol Notes. 4(3):535-538. doi:10.1111/j.1471-8286.2004.00684.x.

701 Vignaud T, Clua E, Mourier J, Maynard J, Planes S. 2013. Microsatellite Analyses of 702 Blacktip Reef Sharks ( Carcharhinus melanopterus ) in a Fragmented Environment Show

703 Structured Clusters. PLOS ONE. 8(4):e61067. doi:10.1371/journal.pone.0061067.

704 Vignaud TM, Mourier J, Maynard JA, Leblois R, Spaet JLY, Clua E, Neglia V, Planes S. 705 2014. Blacktip reef sharks, Carcharhinus melanopterus, have high genetic structure and 706 varying demographic histories in their Indo-Pacific range. Mol Ecol. 23(21):5193-5207. 707 doi:10.1111/mec.12936.

708 Wang J. 2002. An Estimator for Pairwise Relatedness Using Molecular Markers. Genetics. 709 160(3):1203-1215.

710 Wang J. 2007. Triadic IBD coefficients and applications to estimating pairwise relatedness.

711 Genet Res. 89(3):135-153. doi:10.1017/S0016672307008798.

712 Weideli OC, Mourier J, Planes S. 2015. A massive surgeonfish aggregation creates a unique 713 opportunity for reef sharks. Coral Reefs. 34(3):835-835. doi:10.1007/s00338-015-1290-2.

714 Whitehead H. 2008. Analyzing Animal Societies: Quantitative Methods for Vertebrate Social 715 Analysis. Chicago: University of Chicago Press.

716 Whitehead H, Dufault S. 1999. Techniques for Analyzing Vertebrate Social Structure Using 717 Identified Individuals: Review and Recommendations. In: Slater PJB, Rosenblat JS, Snowden 718 CT, Roper TJ, editors. Advances in the Study of Behavior. Vol. 28. Academic Press. p. 33719 74. [accessed 2020 Apr 20].

720 http://www.sciencedirect.com/science/article/pii/S0065345408602156.

721 Whitehead H, James R. 2015. Generalized affiliation indices extract affiliations from social 722 network data. Methods Ecol Evol. 6(7):836-844. doi:10.1111/2041-210X.12383.

723 Wilkinson GS, Carter GG, Bohn KM, Adams DM. 2016. Non-kin cooperation in bats. Phil 724 Trans R Soc B. 371(1687):20150095. doi:10.1098/rstb.2015.0095.

725 Wiszniewski J, Lusseau D, Möller LM. 2010. Female bisexual kinship ties maintain social cohesion in a dolphin network. Anim Behav. 80(5):895-904.

doi:10.1016/j.anbehav.2010.08.013.

730 hierarchical social organization in African elephants. Proc R Soc B Biol Sci.

731 276(1672):3513-3521. doi:10.1098/rspb.2009.0941. 
732 Wolf JBW, Trillmich F. 2008. Kin in space: social viscosity in a spatially and genetically

733 substructured network. Proc R Soc Lond B Biol Sci. 275(1647):2063-2069.

734 doi:10.1098/rspb.2008.0356.

735

736

737 


\section{Table 1: Multiple Regression Quadratic Assignment Procedure and the influence of all}

740 structural variables on shark social associations. Matrices representing structural variables

741 (predictors) were regressed against the association matrix (SRI) using a subset of the individuals

742 in the population $(n=43)$ to which genetic relatedness was available. TO: temporal overlap; SO:

743 spatial overlap; Gregariousness: typical number of associates based on (Godde et al. 2013); Size

744 and Sex: binary matrices where individuals of the same size/sex classes are represented by 1 , and

745 different classes by 0 . Adjusted $\mathrm{R}^{2}$ indicates how much of the variation on association indices

746 was explained by the predictors. Significant predictors in which $P$-values are given by the

747 proportion of times the empirical regression coefficient was smaller or greater than the null

748 expectancy from 20,000 randomisations ( $P$-values are complementary, totalling 1$)$ are indicated

749 in bold. We considered all predictors were significant when $\beta \leq \mathrm{r}$, thus $\mathrm{P}>0.95(* *)$.

750

\begin{tabular}{llrllc}
\hline Period (SRI) & Predictors & Regression Coefficient $(\boldsymbol{\beta})$ & $\boldsymbol{P}(\boldsymbol{\beta} \geq \boldsymbol{r})$ & $\boldsymbol{P}(\boldsymbol{\beta} \leq \boldsymbol{r})$ & Adjusted R $^{2}$ \\
\hline \multirow{2}{*}{ All } & TO & 0.5534 & $1.000^{* *}$ & $<0.001^{*}$ & $94 \%$ \\
& SO & 0.1069 & $1.000^{* *}$ & $<0.001^{*}$ & \\
& Gregariousness & -0.0018 & $<0.001$ & 1.000 \\
& Size & 0.0057 & 0.9101 & 0.0895 & \\
& Sex & -0.0025 & 0.0003 & 0.9996 & \\
\end{tabular}


753 Table 2 Results of Mantel test for the correlation between the simple-ratio association (SRI)

754 and generalized affiliations (GAI) matrices and the pairwise genetic relatedness among

755 individual sharks for each period and each sex relationship. Observed estimates were

756 compared to those of 20,000 estimates from the randomized networks and significant p-

757 values are indicated in bold.

\begin{tabular}{rllll}
\hline Index & SRI & & GAI & \\
& Estimate (rho) & p-value & Estimate (rho) & p-value \\
\hline Male-male & 0.1028 & $\mathbf{0 . 0 2 6 7}$ & 0.0404 & 0.4187 \\
Female-female & -0.0653 & 0.5767 & 0.0361 & 0.7644 \\
Male-female & 0.0136 & 0.8291 & -0.0240 & 0.7050 \\
\hline
\end{tabular}

758

759

760

761 Table 3 Effects of sex on shark gregariousness (degree and strength) in the social network.

\begin{tabular}{llllll} 
& & Coefficient & SE & $t$ statictic & $P_{\text {rand }}$ \\
\hline Degree & Intercept & 17.308 & 1.800 & 9.613 & \\
& Sex (male) & 4.726 & 2.156 & 2.192 & $<\mathbf{0 . 0 0 1}$ \\
Strength & Intercept & 4.493 & 0.468 & 9.596 & \\
& Sex (male) & 0.369 & 0.560 & 0.660 & 0.548 \\
\hline
\end{tabular}

762

763

764

765

766

767

768

769 
770 Table 4 Community level information on structure, association and affiliation indices, and

771 genetic relatedness. For each social index (SRI and GAI) and each community, are reported

772 number of community members (no. of individuals), mean index value, mean genetic

773 relatedness and p-values of the tests for within-between differences in relatedness.

\begin{tabular}{llrrrrr}
\hline \multirow{2}{*}{ Index } & Communities & Modularity Q & $\begin{array}{l}\text { No. of } \\
\text { individuals }\end{array}$ & Mean index (SD) & Mean r (SE) & $p$-values \\
\hline \multirow{2}{*}{ SRI } & Overall & \multirow{2}{*}{0.493} & 43 & $0.133(0.210)$ & $0.071(0.005)$ & 0.093 \\
& Red & 14 & $0.487(0.178)$ & $0.071(0.009)$ & 0.267 \\
& Yellow & 9 & $0.256(0.307)$ & $0.073(0.016)$ & 0.24 \\
& Green & & 20 & $0.282(0.194)$ & $0.069(0.006)$ & 0.11 \\
\multirow{3}{*}{ GAI } & Overall & 0.312 & 43 & $-0.028(0.126)$ & $0.060(0.006)$ & 0.722 \\
& Red & & 1 & $/$ & $/$ \\
& Yellow & & 12 & $0.078(0.147)$ & $0.056(0.010)$ & 0.707 \\
& Green & & $-0.003(0.155)$ & $0.043(0.015)$ & 0.735 \\
& Cyan & 13 & $0.022(0.127)$ & $0.066(0.009)$ & 0.415 \\
& Purple & 11 & $0.053(0.140)$ & $0.061(0.013)$ & 0.408 \\
\hline
\end{tabular}


776 Figure 1 Map of the study location indicating the monitored sites along the $10 \mathrm{~km}$ reef edge

777 of the North coast of Moorea.
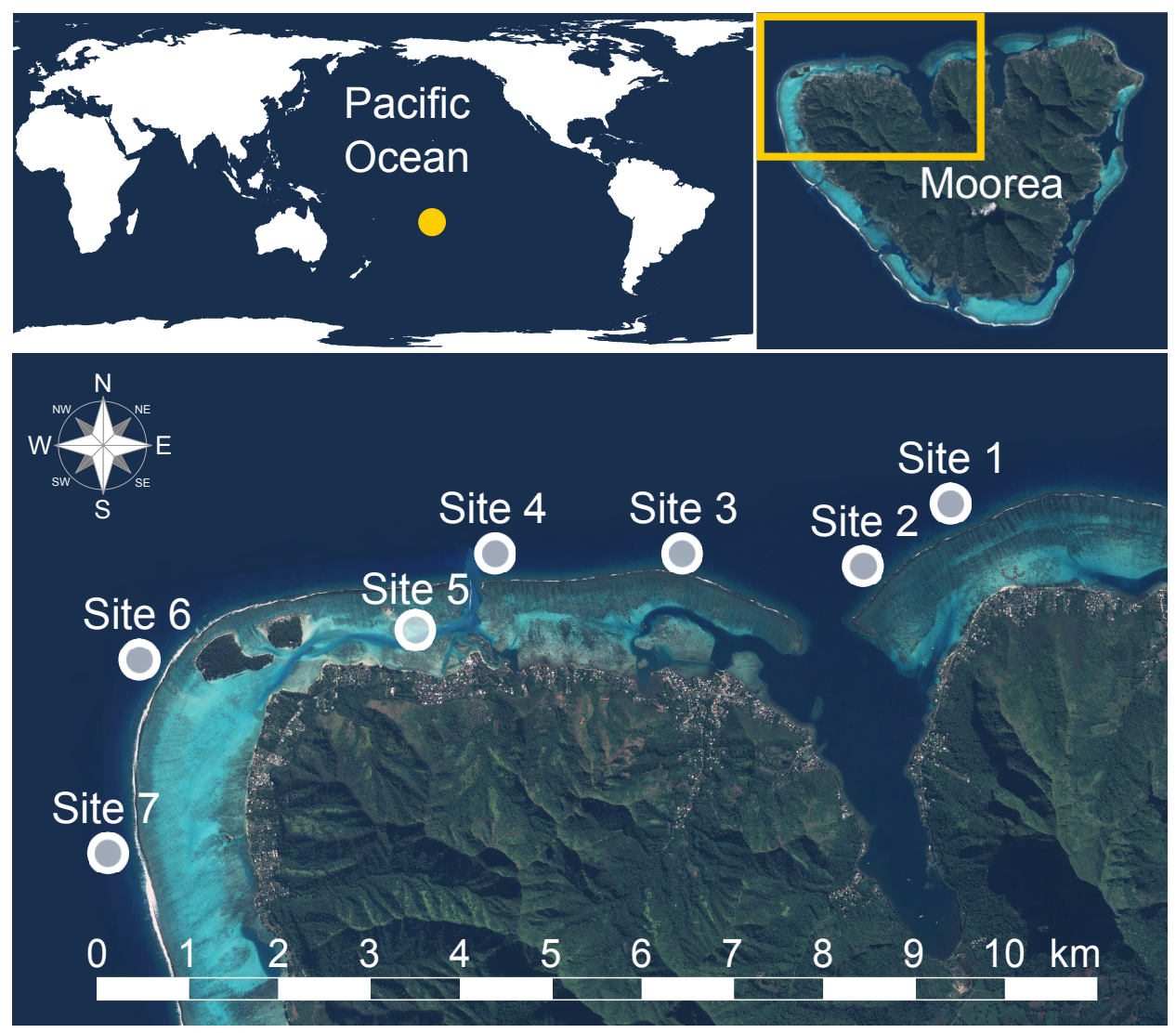

778

779 Figure 2 Shark social preferences at the individual and population levels. Nodes $(\mathrm{N}=43$;

780 male:female $=30: 13$ ) representing photo-identified individuals are proportional to their size

781 and colour-coded by social modules; individuals are connected by links whose thicknesses

782 are proportional to SRI in the association networks (left panel), and to GAI removing

783 confounding factors in the affiliation networks where only positive GAIs are plotted (right

784 panel). In the density plots, red dots denote statistically significant observed values, shaded

785 distributions indicate null expectancy and blue whiskers indicate 95\% confidence intervals.

786 The shark social network is characterized by (a) significant standard deviations (SD) of SRI

787 and GAI indicating social preferences and (b) significant modularity (Q) indicating social 
788 division. In (c) are represented the density distribution of sightings of social community

789 members.

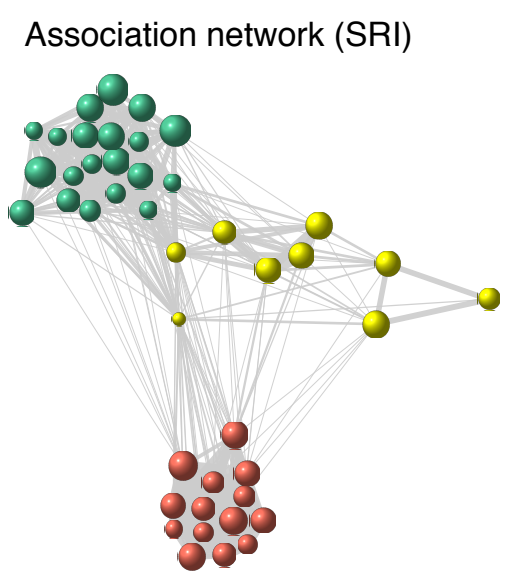

(a)

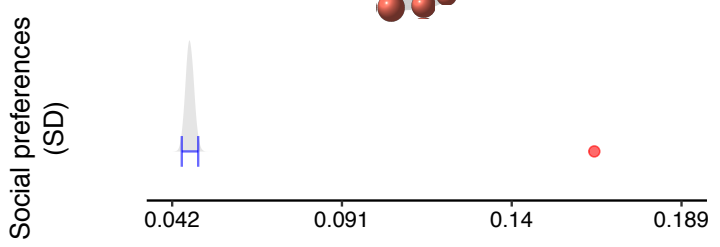
Affiliation network (GAI)

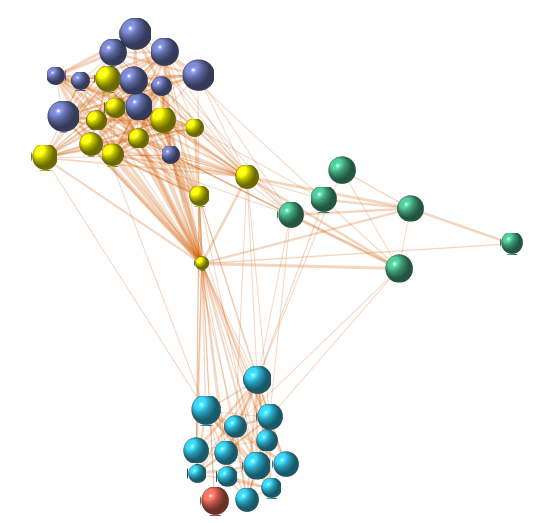

(b)
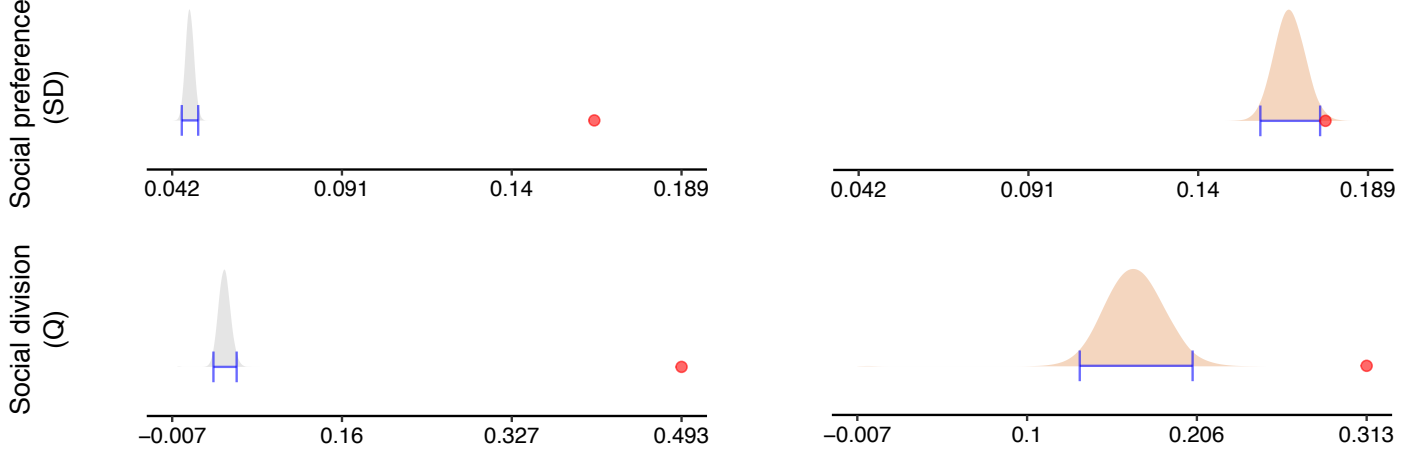

(c)
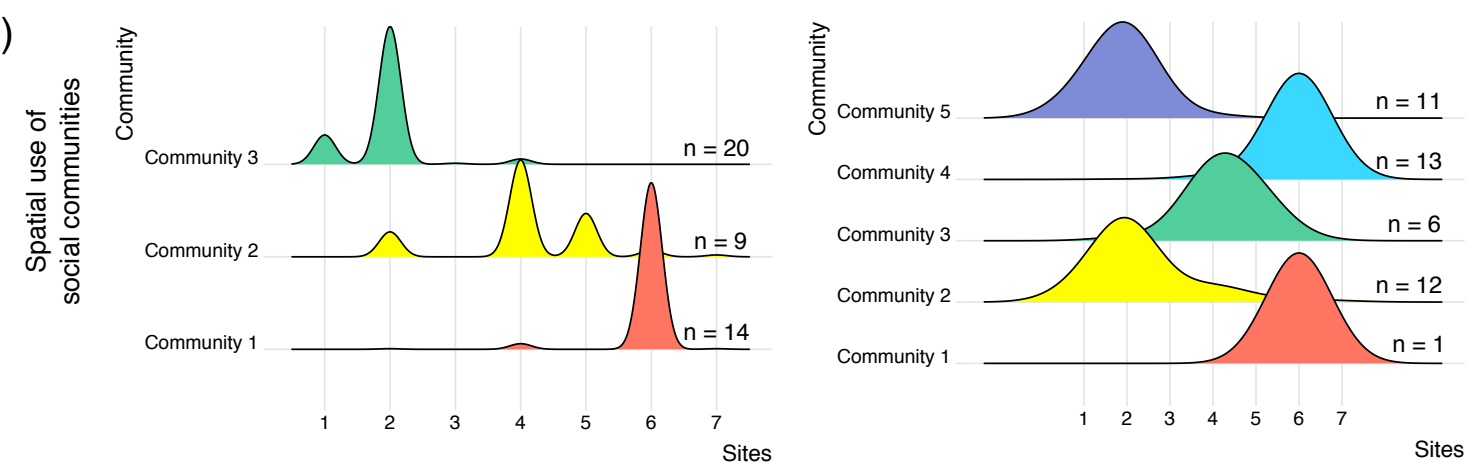

792 Figure 3 (a) Genetic network using the same layout as in Figure 2 where nodes $(\mathrm{N}=43$;

793 male:female $=30: 13$ ) are proportional to individual size and colour-coded by sex (males in

794 grey and females in white) and edges are proportional to genetic relatedness in the genetic

795 network (only close kin are plotted, i.e. $r>0.25$ ). (b) Differences in gregariousness (degree

796 and strength) of individual sharks between males and females (colours: pink indicates 
797 females and blue indicates males). Comparison of the coefficient from the GLM based on the

798 observed data (red vertical line) and the frequency distribution of coefficients from the same

799 model based on the randomized data are indicated over each box plot to report significance of

800 the difference. (c) Relationship between association and affiliation indices and the triadic

801 likelihood estimator (TrioML) of genetic relatedness in male-male, female-female and male-

802 female pairs.

(a)

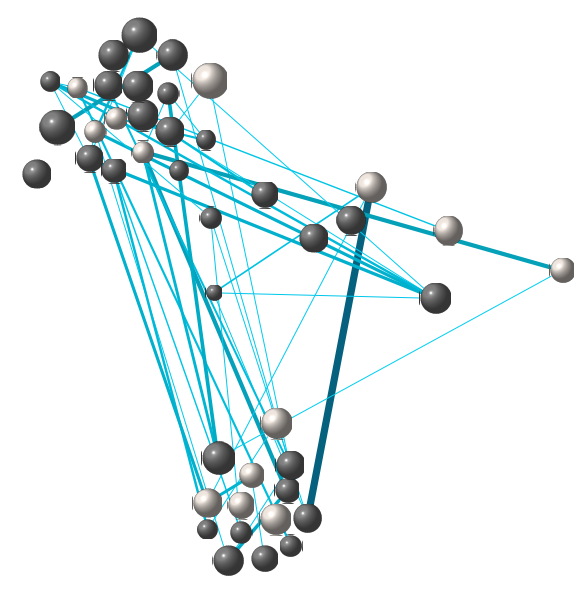

(b)
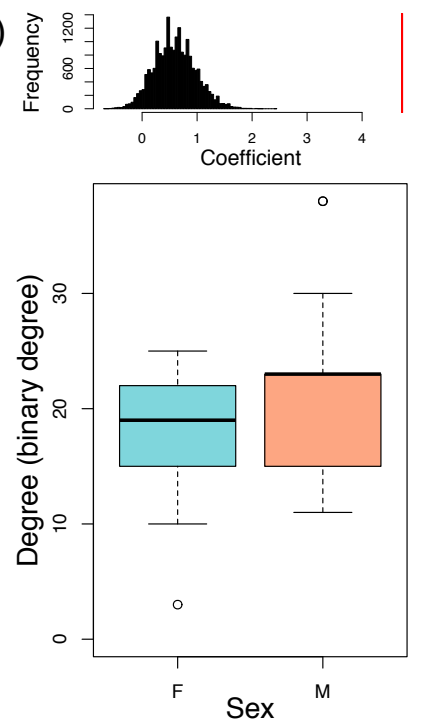

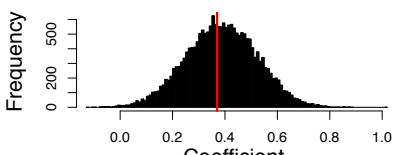

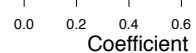

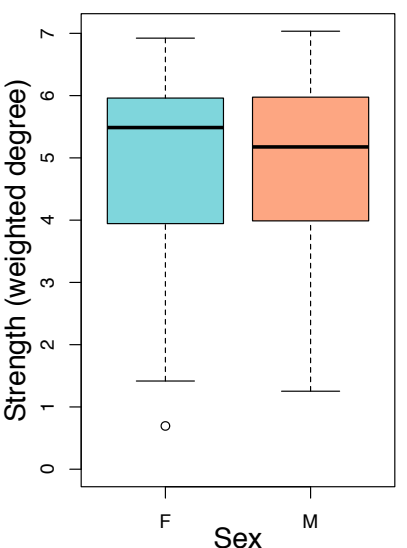

(c)
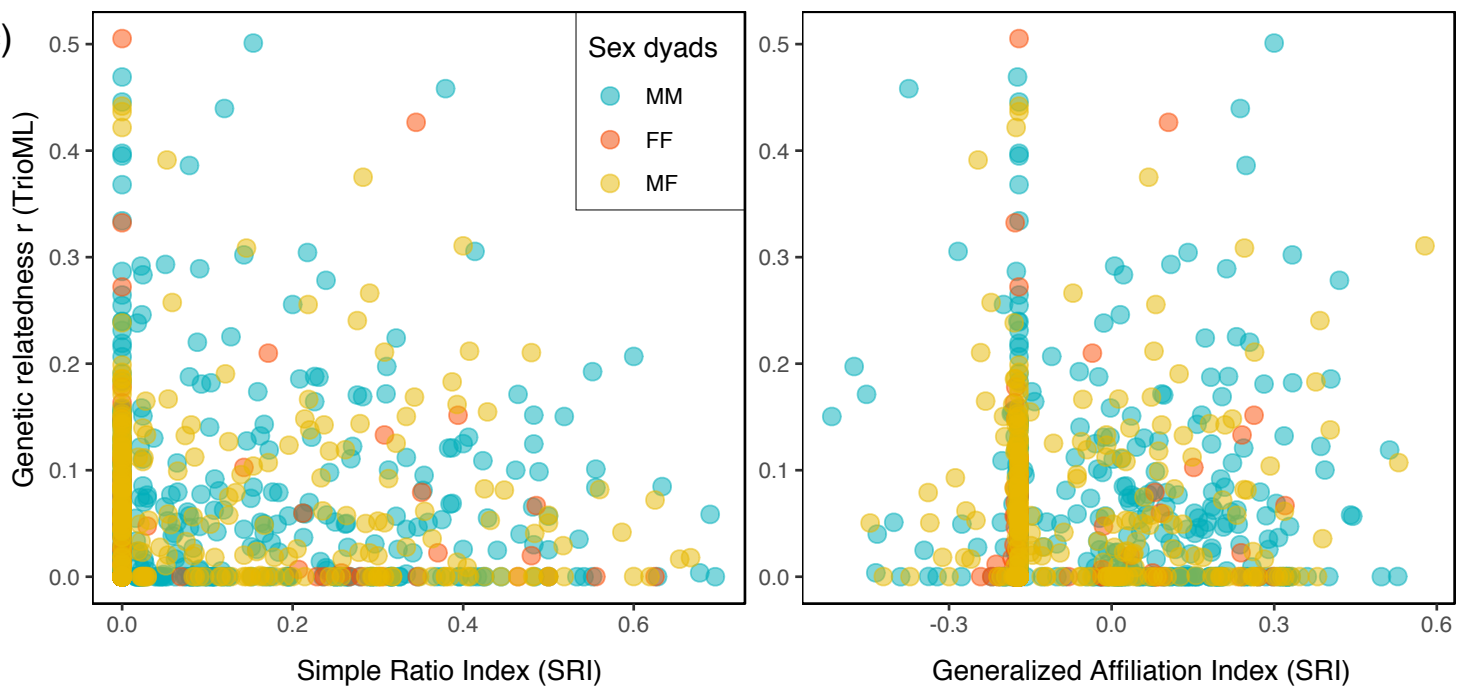

803

804 
806 Figure 4 Numbers of close kin ( $r>0.25$, the expected value of half-sibs) within and between

807 social communities for association (SRI) and affiliation (GAI) indices.

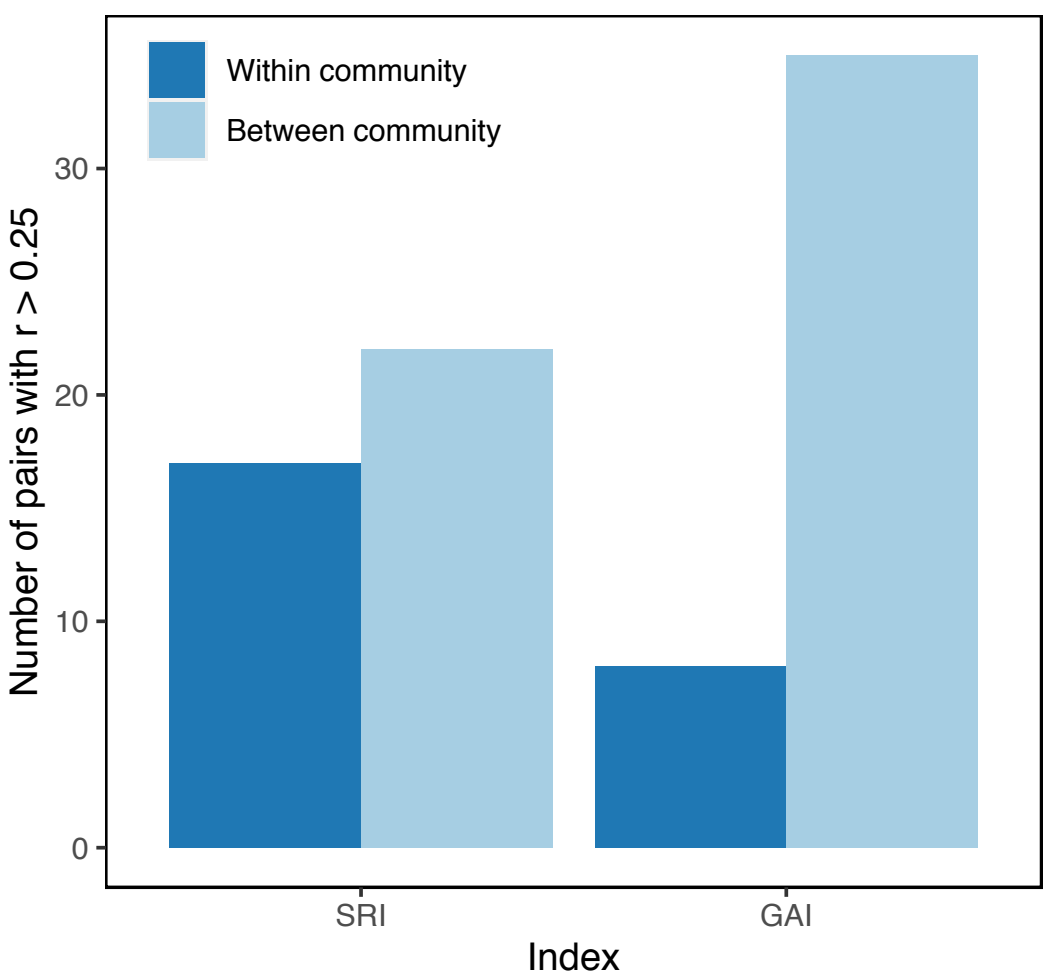

808 